\title{
Investing in all of Our Children: Global Pediatric Surgery for the Twenty-First Century
}

\author{
Tamara N. Fitzgerald ${ }^{1} \cdot$ Henry E. Rice ${ }^{1}$
}

Published online: 4 March 2019

(C) Société Internationale de Chirurgie 2019

Remarkable gains have been made in global health over the past 25 years, including reduction in child mortality in many low- and middle-income countries (LMICs) [1]. However, the provision of high-quality surgical care for children continues to present a critical global health challenge. Children with surgical needs represent a high burden of disease, and the lack of access to surgical care continues to threaten the health of millions of children around the world as well as limit economic growth and development [2]. Several high-profile initiatives have focused attention on gaps in surgical care for adults across LMICs, including the third edition of the Disease Control Priorities project [3], the Lancet Commission on Global Surgery (LCoGS) [4], and the World Health Assembly Resolution A68/15 [5]. Despite these outstanding efforts, the surgical care for children continues to be largely overlooked within the global health agenda.

Over recent years, there have been several attempts to improve attention to the surgical care for children in LMICs. In 2014, the Seminars in Pediatric Surgery published a series of reports which proposed that improvements in surgical care for children in LMICs are technically feasible and that childhood mortality related to surgical conditions could be reduced through improvements in health systems [6]. In this current issue of the World Journal of Surgery, we assess interval progress in the surgical care for children and reflect on the future of surgical care for children within the context of the Sustainable Development Goals (SDG), particularly SDG 3.2

Tamara N. Fitzgerald tamara.fitzgerald@duke.edu

1 Department of Surgery, Duke University School of Medicine, Box 3815, DUMC, Durham, NC 27705, USA which aims to end preventable deaths of newborns and children under the age of five by 2030 [7].

Much progress has been made over recent years to improve the surgical care of children around the world. The Global Initiative for Children's Surgery (GICS) is an international consortium of providers from across specialties committed to improving the surgical care of children in LMICs [8]. Advances in national datasets, informatics, and training programs [9] have improved workforce and research gaps in surgical care for children. Several policy leaders and donor groups, such as Kids OR, have made investment in surgical infrastructure for children a global health priority [10].

As detailed in the following reports, surgical conditions in children continue to represent a high burden of disease in the world's poorest regions. In the absence of accessible surgical care, case fatality rates for children remain high for common, easily treatable surgical conditions, including appendicitis, hernia, fractures, and congenital anomalies [11]. The lack of surgical care threatens the function of robust health systems for children [12]. Major research gaps continue in surgical care for children, such as understanding of the role of health system strengthening on mortality related to surgical disease. This slow progress underscores the need to improve research capacity and metrics, identify underperforming countries in surgical care for children, and assist providers and health systems to scale up surgical infrastructure, training, and new health technologies.

In this symposium, we have brought together reports from new and established leaders in the field of global children's surgery. These reports highlight the following:

- From Garber et al., a discussion of the heterogeneity of pediatric global surgery. "Global Surgery" is a broad 
term that describes the challenges faced by billions of patients and surgeons across the world in their attempt to access and deliver care. However, these challenges are diverse across geographic regions. While some regions may struggle with workforce capacity, others may suffer instability from political violence, while others may lack quality initiatives. These needs require that healthcare leaders engage with their local health systems to address pediatric surgery challenges [13].

- From Ameh and Butler, detailed recommendations for required infrastructure for the provision of safe, highquality surgical care for children. This report describes the role of physical structures as well as equipment and supplies, as well as integration of infrastructure with appropriate children's surgery workforce [14].

- From Smith et al., a summary of the economic benefits of investing in surgery for children. Pediatric global surgery continues to suffer from the misconception that surgery is an expensive intervention compared to other global health priorities. However, the value of surgical provision in LMICs has been demonstrated to be a good investment through cost-effectiveness of scaling up surgical services, providing financial risk protection to individuals, and bolstering the economic output of financially strained countries [15].

- From Poenaru and Seyi-Olajide, a description of novel metrics to quantify needs and progress in global surgery for children. Although several global surgical metrics exist, most have not been applied to children's surgery, leaving gaps in our ability to define the burden of disease and needed resources. These metrics can help set targets to monitor system performance and facilitate policy development [16].

- From Kisa et al., a summary of the role of interdisciplinary collaborations to improve the surgical care of children. This summary builds from experiences with partnerships in pediatric oncology, neonatology, and community health worker networks and presents the role of these collaborations on the scale-up of surgical services for children. This report summarizes a 2015 stakeholder's conference in Uganda and analyzes impact on quality and capacity of partnerships [17].

- From the collaborators in the Global Initiative for Children's Surgery (GICS), a summary of efforts to build an interdisciplinary group of providers from highincome countries and LMICs to develop priorities to improve the surgical care of children. These efforts include infrastructure, service delivery, training, and research. GICS has developed the Optimal Resources for Children's Surgery (OReCS) program, which details guidelines for healthcare systems to manage the surgical needs of children at primary health centers, first-, second-, and third-level hospitals, and national children's hospitals [18].

- From Krishnaswamy et al., a discussion of ethics in global pediatric surgery. With the evolution of global surgery from an individual-focused mission trip model toward development of systems for surgical care within global health, new complex ethical dilemmas emerge. At the heart of this transformation lies global pediatric surgery with its particularly vulnerable patient population, need for unique resources and expertise, and focus on multidisciplinary care. The authors review the development of global surgery ethics, examine how these paradigms fit within the recent changes to global surgical care, and propose new ethical dilemmas for consideration [19].

We thank the contributing authors for their valuable time and contributions over many years to further the progress in global pediatric surgery. As these reports demonstrate, there are many in-country champions and global partners working together to solve these difficult problems. It is our great privilege to be part of this global community.

\section{References}

1. Ogbuoji O, Qi J, Olson ZD et al (2017) Annual rates of decline in child, maternal, tuberculosis, and noncommunicable disease mortality across 109 low- and middle-income countries from 1990 to 2015. In: Jamison DT, Gelband H et al (eds) Disease control priorities: improving health and reducing poverty. The International Bank for Reconstruction and Development/The World Bank, Washington

2. Yousef Y, Lee A, Ayele F, Poenaru D (2018) Delayed access to care and unmet burden of pediatric surgical disease in resourceconstrained African countries. J Pediatr Surg. https://doi.org/10. 1016/j.jpedsurg.2018.06.018

3. Jamison DT, Alwan A, Mock CN et al (2018) Universal health coverage and intersectoral action for health: key messages from Disease Control Priorities, 3rd edition. Lancet 391(10125): 1108-1120

4. Meara JG, Leather AJ, Hagander L et al (2015) Global Surgery 2030: evidence and solutions for achieving health, welfare, and economic development. Lancet 386(9993):569-624

5. Strengthening emergency and essential surgical care and anaesthesia as a component of universal health coverage. 2015. http:// apps.who.int/gb/ebwha/pdf_files/WHA68/A68_R15-en.pdf?ua= 1. Accessed 11 Sept 2018

6. Farmer DL, Bickler SW (2016) Preface. Semin Pediatr Surg 25(1):1-2

7. Sustainable Development Goals. https://sustainabledevelopment. un.org/SDG3. Accessed 11 Sept 2018

8. Goodman LF, St-Louis E, Yousef Y et al (2018) The Global Initiative for Children's Surgery: optimal resources for improving care. Eur J Pediatr Surg 28(1):51-59

9. Krishnaswami S, Nwomeh BC, Ameh EA (2016) The pediatric surgery workforce in low- and middle-income countries: problems and priorities. Semin Pediatr Surg 25(1):32-42 
10. Yap A, Muzira A, Cheung M et al (2018) A cost-effectiveness analysis of a pediatric operating room in Uganda. Surgery 164(5):953-959

11. GlobalSurg Collaborative (2016) Determinants of morbidity and mortality following emergency abdominal surgery in children in low-income and middle-income countries. BMJ Global Health 1(4): 0000091

12. Cairo SB, Kalisya LM, Bigabwa R, Rothstein DH (2018) Characterizing pediatric surgical capacity in the Eastern Democratic Republic of Congo: results of a pilot study. Pediatr Surg Int 34(3):343-351

13. Garber K, Cabrera CCR, Dinh QL et al (2018) The heterogeneity of global pediatric surgery: defining needs and opportunities around the world. World J Surg. https://doi.org/10.1007/s00268018-04884-x [Epub ahead of print]

14. Ameh EA, Butler MW (2019) Infrastructure expansion for children's surgery: models that are working. World J Surg. https:// doi.org/10.1007/s00268-018-04894-9 [Epub ahead of print]

15. Smith ER, Concepcion TL, Niemeier KJ, Ademuyiwa AO (2018) Is global pediatric surgery a good investment? World J Surg. https://doi.org/10.1007/s00268-018-4867-4 [Epub ahead of print]
16. Poenaru D, Seyi-Olajide JO (2018) Developing metrics to define progress in children's surgery. World J Surg. https://doi.org/10. 1007/s00268-018-4868-3 [Epub ahead of print]

17. Kisa P, Grabski DF, Ozgediz D et al (2019) Unifying children's surgery and anesthesia stakeholders across institutions and clinical disciplines: challenges and solutions from Uganda. World J Surg. https://doi.org/10.1007/s00268-018-04905-9 [Epub ahead of print]

18. Global Initiative for Children's Surgery (2019) Global Initiative for Children's Surgery: a model of global collaboration to advance the surgical care of children. World J Surg. https://doi. org/10.1007/s00268-018-04887-8 [Epub ahead of print]

19. Cunningham AJ, Stephens CQ, Ameh EA, et al. (2019) Ethics in global pediatric surgery: Existing dilemmas and emerging challenges. World J Surg (in press)

Publisher's Note Springer Nature remains neutral with regard to jurisdictional claims in published maps and institutional affiliations. 